\title{
Evaluation of Antidiabetic and Antihyperlipidemic Effects of Peganum harmala Seeds in Diabetic Rats
}

\author{
Gholamreza Komeili, ${ }^{1}$ Mohammad Hashemi, ${ }^{2}$ and Mohsen Bameri-Niafar ${ }^{1}$ \\ ${ }^{1}$ Department of Physiology, School of Medicine, Zahedan University of Medical Sciences, Zahedan 98167-43181, Iran \\ ${ }^{2}$ Department of Clinical Biochemistry, School of Medicine, Zahedan University of Medical Sciences, Zahedan 98167-43181, Iran \\ Correspondence should be addressed to Mohammad Hashemi; mhd.hashemi@gmail.com
}

Received 28 December 2015; Accepted 31 March 2016

Academic Editor: Abdelouahed Khalil

Copyright @ 2016 Gholamreza Komeili et al. This is an open access article distributed under the Creative Commons Attribution License, which permits unrestricted use, distribution, and reproduction in any medium, provided the original work is properly cited.

\begin{abstract}
The present study was carried out to investigate the antidiabetic and antihyperlipidemic properties of hydroalcoholic extract of Peganum harmala in streptozotocin-induced diabetic male rats. In an experimental study, 64 normal Wistar albino male rats (200$230 \mathrm{~g}$ ) were randomly divided into 8 groups. Control and diabetic rats were treated with normal saline and three different doses (30, 60 , and $120 \mathrm{mg} / \mathrm{kg}$ ) of hydroalcoholic extract of Peganum harmala seeds for 4 weeks orally. At the end of treatment, blood samples were taken and glucose, triglycerides, total cholesterol, LDL-c, HDL-c, malondialdehyde (MDA), total antioxidant capacity (TCA), ALT, AST, GGT, bilirubin, and glycosylated hemoglobin $\left(\mathrm{HbA}_{1 \mathrm{C}}\right)$ were determined. STZ-induced diabetic rats showed significant changes in the values of glucose, triglycerides, total cholesterol, LDL-c, MDA, TAC, ALT, AST, GGT, bilirubin, and HbA ${ }_{1 C}$ in comparison with normal rats. Administration of the extract to diabetic rats resulted in a remarkable decrease in glucose, lipid profiles, MDA, ALT, AST, GGT, bilirubin, and $\mathrm{HbA}_{1 \mathrm{C}}$ levels and increase in TAC relative to diabetic group. The results of this study indicated that hydroalcoholic extract of Peganum harmala seeds possesses antidiabetic and hypolipidemic activities and could be useful in treatment of diabetes.
\end{abstract}

\section{Introduction}

Diabetes mellitus (DM) is a group of metabolic disorders characterized by circulating hyperglycemia resulting from either defect in insulin secretion or insulin action. According to the international diabetes federation (IDF), it was estimated that more than 382 million people throughout the world had diabetes in 2013. Its prevalence is increasing rapidly, particularly in developing countries, and is expected to rise to 552 million by 2030 [1]. According to the latest evaluations of the World Health Organization (WHO), the global prevalence of diabetes in adult was 9\% in 2014. In 2012 diabetes was the direct cause of 1.5 million deaths. More than $80 \%$ of diabetes deaths occur in low- and middle-income countries [2]. Subjects with diabetes have an increased risk of developing a number of serious health problems. Consistently high blood glucose levels can lead to serious diseases affecting the heart and blood vessels, eyes, kidneys, nerves, and teeth period. In addition, people with DM also have a higher risk of developing infections.

Various treatment options are available such as lifestyle modifications, proper nutritional management, and oral medication [3].

Animal models have been used generally for assessment of the etiology of diabetes complications. The pathogenesis of DM and its complications are associated with the overproduction of reactive oxygen species (ROS) and reduction of the endogenous antioxidant system (enzymatic and nonenzymatic), leading to oxidative stress [4]. Streptozotocin (STZ) is the most commonly used agent to induce experimental diabetes model [5]. The antidiabetogenic, cholesterol-lowering, anti-inflammatory, and other metabolically beneficial qualities of phytochemicals from various plant extracts have been evaluated in a number of animal and human studies [6]. Iran is fortunate to have such a varied climate in which virtually 
approximately any medicinal plant can grow. The use of medicinal plants has increased as an alternative for the treatment of diabetes because modern medicines are identified with several side effects and are also expensive [7]. Peganum harmala is customarily and usually used for medicinal purposes since ancient times [8]. This plant is widely scattered and used as medicinal plant in central Asia, North Africa, and Middle East [9]. The root and seeds enclose several alkaloids that are pharmacologically active and accountable for their effects. Phytochemical studies of Peganum harmala led to the isolation of different types of chemical ingredients such as alkaloids, steroids, and flavonoids from seeds, leaves, flowers, stems, and roots [10]. Peganum harmala is rich in alkaloids of $\beta$-carbolines derivatives [11]. These alkaloids have a broad spectrum of potent therapeutic activities such as anticancer $[12,13]$, analgesic, and antinociceptive [14]. It has been shown that Peganum harmala has hypoglycemic and cytoprotective effects $[7,15]$.

In this study, we aimed to evaluate the effect of hydroalcoholic extract of Peganum harmala on blood glucose, lipid profile, liver function tests, and malondialdehyde (MDA) and total antioxidant capacity (TAC) in diabetic rats.

\section{Materials and Methods}

2.1. Rats. Streptozotocin (STZ) was obtained from Sigma Chemical Company. All experimental procedures were approved by local ethics committee of Zahedan University of Medical Sciences. 64 normal adult male Wistar albino rats weighing 200-230 g were chosen and housed in single cages under standard laboratory conditions (temperature 23 $\pm 2^{\circ} \mathrm{C}, 12 \mathrm{~h}$ light and dark cycle) for one week aimed at acclimatization [16]. Animals are fed with standard pellet diet and water ad libitum.

Then rats were allocated in 8 groups randomly ( 8 in each group). These groups include intact group, three control groups that received daily 30,60 , and $120 \mathrm{mg} / \mathrm{kg}$ extract of Peganum harmala, respectively, diabetic group, and three diabetic groups that received 30,60, and $120 \mathrm{mg} / \mathrm{kg}$ extract of Peganum harmala, respectively. Duration of experiments was four weeks and water and food intake measured daily. After emphasis of diabetes, animals were treated with hydroalcoholic extract of Peganum harmala seeds at 30, 60, and $120 \mathrm{mg} / \mathrm{kg}$ orally for four weeks. All experiments started at 9:00 every day.

\subsection{Preparation of Hydroalcoholic Extract of Peganum har-} mala. The seeds of Peganum harmala were collected from Zahedan in 2014. Plant was identified and authenticated by Botany Department of Sistan and Baluchestan University. Powdered seed of Peganum harmala $(20 \mathrm{~g})$ was placed in Soxhlet system with ethanol (70\%) for 8 hours. Then extract dried in incubator $\left(37^{\circ} \mathrm{C}\right)$ to give a final yield of approximately $10 \%$ hydroalcoholic extract of seeds. In time of experiments, the extract was dissolved in normal saline and animals were force-fed with above-mentioned doses.

2.3. Induction of Diabetes. Overnight fasted animals were made diabetic by intravenous injection of streptozotocin
(STZ) at $50 \mathrm{mg} / \mathrm{kg}$ of body weights [17]. Blood glucose (BG) level was measured after 72 hours and animals showing BG level over $250 \mathrm{mg} / \mathrm{dL}$ were considered diabetic [18]. At the end of experiments, animals were killed by decapitation after overnight fasting and blood samples were taken in tubes with and without anticoagulant. Biochemical parameters such as blood glucose, triglyceride, total cholesterol, HDL-c, alanine aminotransferase (ALT), aspartate aminotransferase (AST), gamma glutamyl transferase (GGT), and bilirubin were determined using commercial available kits (Pars Azmoon, Tehran) by an automatic biochemistry analyzer ( $\mathrm{T}$ 1500, Italy). LDL-c value was calculated by Friedewald equation. $\mathrm{HbA}_{1 \mathrm{C}}$ values were measured using commercial available kit (Pishtazteb, Iran).

Serum malondialdehyde (MDA) level was measured as the end product of lipid peroxidation by the thiobarbituric acid (TBA) reaction method as described previously [19]. Total antioxidant capacity was measured with ferric reducing ability of plasma (FRAP) method as described previously $[20,21]$.

2.4. Statistical Analysis. Data are presented as mean \pm SD. Statistical analysis was done by SPSS software version 17 (SPSS, Inc., Chicago, Il, USA). Comparison of the data between groups was performed using one-way analysis of variance (ANOVA) followed by Tukey's post hoc test. $P<$ 0.05 were considered statistically significant.

\section{Results}

Our findings indicated that induction of T1DM causes the increased food and water intake and decrease in body weight significantly compared to intact group $(P<0.01)$. As shown in Table 1 , consumption of extracts in nondiabetic and diabetic animals did not significantly have an effect on body weight to water and food intake $(P>0.05)$. There is no significant difference in body weight and food and water intake at start of experiments $(P>0.05)$.

Also, the data showed that diabetes induction causes a significant increase in glucose, triglyceride, total cholesterol, and LDL-c $(P<0.01)$ and decrease in HDL-c $(P<$ 0.05 ), whereas administration of Peganum harmala causes significant decrease in glucose (in all doses, $P<0.001$ ), total cholesterol (in doses of 60 and $120 \mathrm{mg} / \mathrm{kg}, P<0.01$ ), and LDL-c (in all doses of extract, $P<0.01$ ), increase in HDL-c (in all doses of extract, $P<0.01$ ) in comparison with diabetic group (Table 2), and no effect on triglyceride level.

Figure 1 shows that $\mathrm{HbA}_{1 \mathrm{C}}$ increased significantly in diabetic animals $(P<0.001)$ and consumption of extract decreases the $\mathrm{HbA}_{1 \mathrm{C}}$ in doses of $60 \mathrm{mg} / \mathrm{kg}(P<0.01)$ and $120 \mathrm{mg} / \mathrm{kg}(P<0.001)$ compared with diabetic group.

We evaluated the effect of induction of diabetes on oxidative stress indices such as MDA and TAC. The MDA increased significantly while the TAC decreased significantly after induction of diabetes. Administration of extract causes a decrease in MDA (in all doses of extract, $P<0.01$ ) and increase in TAC (in all doses of extract, $P<0.01$ ) (Figures 2 and 3 ). 
TABLE 1: The mean of body weight $(\mathrm{g})$ and daily food $(\mathrm{g})$ and water intake $(\mathrm{mL})$ per animal in all groups (data are shown as mean \pm SD, $n=8)$.

\begin{tabular}{lcccc}
\hline Groups & Initial weight $(\mathrm{g})$ & Final weight $(\mathrm{g})$ & Food intake $(\mathrm{g})$ & Water intake $(\mathrm{mL})$ \\
\hline Intact & $229.6 \pm 16.9$ & $265 \pm 17$ & $17.25 \pm 1.2$ & $39.4 \pm 3.9$ \\
Control $+30 \mathrm{mg} / \mathrm{kg}$ extract & $228.8 \pm 13.9$ & $263.6 \pm 18$ & $17.4 \pm 1.6$ & $41.8 \pm 5.9$ \\
Control $+60 \mathrm{mg} / \mathrm{kg}$ extract & $223.1 \pm 21.4$ & $258.5 \pm 24.8$ & $16.4 \pm 1.6$ & $41.8 \pm 5.7$ \\
Control $+120 \mathrm{mg} / \mathrm{kg}$ extract & $229.8 \pm 18.2$ & $255.3 \pm 20.1$ & $15.6 \pm 1.3$ & $42.4 \pm 7.1$ \\
Diabetic & $237 \pm 7.5$ & $194.5 \pm 15.2^{*}$ & $35.9 \pm 2.8^{*}$ & $141.6 \pm 26.8^{*}$ \\
Diabetic $+30 \mathrm{mg} / \mathrm{kg}$ extract & $233.9 \pm 10.4$ & $189.1 \pm 20.7$ & $33.3 \pm 2.9$ & $143.7 \pm 29.4$ \\
Diabetic $+60 \mathrm{mg} / \mathrm{kg}$ extract & $234 \pm 9.5$ & $188.6 \pm 19.9$ & $35.1 \pm 2.4$ & $135.5 \pm 25.2$ \\
Diabetic $+120 \mathrm{mg} / \mathrm{kg}$ extract & $220.5 \pm 11.4$ & $182.8 \pm 8.4$ & $30.2 \pm 3.6$ & $119.0 \pm 11.6$ \\
\hline
\end{tabular}

${ }^{*}$ Statistically significant.

TABLE 2: The mean values of fasting glucose and lipids (mg/dL) profile in serum of all groups (data shown as mean \pm SD, $n=8$ ).

\begin{tabular}{lccccc}
\hline Groups & FBG $(\mathrm{mg} / \mathrm{dL})$ & Triglyceride $(\mathrm{mg} / \mathrm{dL})$ & Total cholesterol $(\mathrm{mg} / \mathrm{dL})$ & HDL-c $(\mathrm{mg} / \mathrm{dL})$ & LDL-c $(\mathrm{mg} / \mathrm{dL})$ \\
\hline Intact & $99.4 \pm 17.8$ & $67 \pm 8.8$ & $66.5 \pm 6.7$ & $31.3 \pm 3.2$ & $23.1 \pm 4.8$ \\
Control + 30 mg/kg extract & $85.9 \pm 10$ & $72.5 \pm 18.9$ & $68.8 \pm 7.2$ & $32.4 \pm 4.1$ & $22 \pm 2.7$ \\
Control + $60 \mathrm{mg} / \mathrm{kg}$ extract & $85.0 \pm 18.0$ & $50.8 \pm 13.5$ & $64 \pm 12.4$ & $31.5 \pm 6.3$ & $22.8 \pm 7.3$ \\
Control + $120 \mathrm{mg} / \mathrm{kg}$ extract & $99.6 \pm 15.4$ & $68.1 \pm 20.1$ & $67.4 \pm 8$ & $31.5 \pm 4.2$ & $22.4 \pm 4.2$ \\
Diabetic & $524.7 \pm 75.6^{*}$ & $91 \pm 8.1^{*}$ & $95.7 \pm 4.2^{*}$ & $25.6 \pm 4.8^{*}$ & $43.9 \pm 12.8^{*}$ \\
Diabetic + 30 mg/kg extract & $370.0 \pm 111.7$ & $82.2 \pm 10.7$ & $80.6 \pm 9.7$ & $35.1 \pm 4.9$ & $32.9 \pm 6.8$ \\
Diabetic + $60 \mathrm{mg} / \mathrm{kg}$ extract & $311.5 \pm 59.5$ & $70 \pm 12.5$ & $77.4 \pm 14.4$ & $34.5 \pm 7.2$ & $26.3 \pm 6.6$ \\
Diabetic $+120 \mathrm{mg} / \mathrm{kg}$ extract & $282.3 \pm 45.3$ & $69 \pm 5.4$ & $73 \pm 6.2$ & $45 \pm 2.1$ & $28.5 \pm 3.1$ \\
\hline
\end{tabular}

${ }^{*}$ Statistically significant.

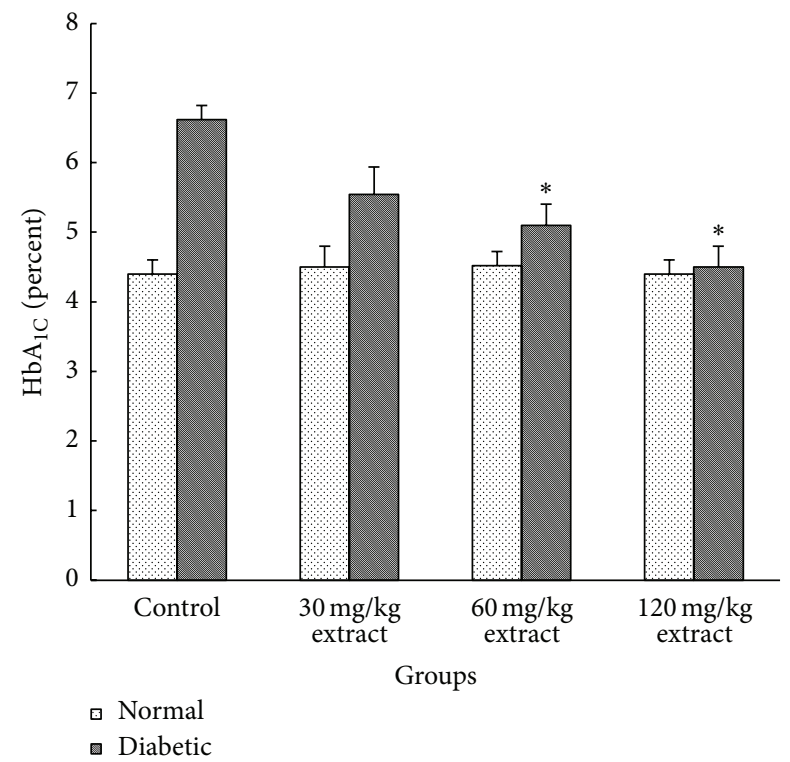

FIgURE 1: The mean value of $\mathrm{HbA}_{1 \mathrm{C}}$ in all different groups (data are shown in mean \pm SEM, $n=8) .{ }^{*} P<0.01$ in comparison with control diabetic group.

Induction of diabetes leads to significantly increased ALT, AST, and GGT activities as well as total bilirubin level in comparison to control groups (Table 3). After administration of Peganum harmala extract (in doses of 60 and $120 \mathrm{mg} / \mathrm{kg}$ ), the mean values of hepatic functional indices such as ALT,
AST, GGT, and bilirubin decreased significantly $(P<0.01)$ to normal range in dose dependent manner.

\section{Discussion}

This study was performed to find out the effect of oral administration of the hydroalcoholic extract of Peganum harmala seeds for 4 weeks on plasma glucose and lipid profile in diabetic male rats. Streptozotocin-induced diabetic rats showed significant increase in blood glucose as well as changes in lipid profile in comparison with normal rats. Our findings revealed that the hydroalcoholic extract of Peganum harmala seeds for 4 weeks significantly decreased the levels of glucose, triglyceride, cholesterol, and LDL-c and increased the level of HDL-c in diabetic rats. Singh et al. [7] showed that ethanolic extract of Peganum harmala seed significantly decreased $(P<0.001)$ blood glucose level in normal and diabetic rats at doses of 150 and $250 \mathrm{mg} / \mathrm{kg}$ of body weight.

Peganum harmala has been traditionally used to treat diabetes in folk medicine of some parts of the world [22]. It has been shown that methanolic extract of Peganum harmala has anticoccidial effects against Eimeria tenella [23]. Ethanol extract of Peganum harmala has been shown to be efficient in the treatment of cutaneous leishmaniasis [24]. There is an inverse association between dietary intakes of flavonoids and risk of cancer [25].

Flavonoids are naturally occurring phenolic compounds (i.e., flavonols, flavones, flavanones, flavan-3-ols, and anthocyanins) that are distributed in plants. They comprise wide 
TABLE 3: Mean values of AST, ALT, GGT, and bilirubin in all groups (data shown as mean $\pm \mathrm{SD}, n=8,{ }^{*} P<0.05$ compared to diabetic group, and ${ }^{* *} P<0.01$ compared to control group).

\begin{tabular}{lcccc}
\hline Groups & AST (IU/L) & ALT (IU/L) & GGT (IU/L) & Bilirubin (mg/dL) \\
\hline Intact & $146.25 \pm 29.4$ & $58 \pm 13$ & $22.1 \pm 6.3$ & $0.37 \pm 0.02$ \\
Control + 30 mg/kg extract & $157 \pm 48.3$ & $60 \pm 10$ & $22.6 \pm 6.9$ & $0.38 \pm 0.01$ \\
Control + $60 \mathrm{mg} / \mathrm{kg}$ extract & $156.4 \pm 32.2$ & $57 \pm 8$ & $22 \pm 2.4$ & $0.37 \pm 0.01$ \\
Control + $120 \mathrm{mg} / \mathrm{kg}$ extract & $141.2 \pm 28.8$ & $65 \pm 5.5$ & $21.5 \pm 3.9$ & $0.39 \pm 0.02$ \\
Diabetic & $383.8 \pm 134^{* *}$ & $84.2 \pm 3.9^{* *}$ & $36.1 \pm 4.6^{* *}$ & $0.53 \pm 0.08^{* *}$ \\
Diabetic + 30 mg/kg extract & $317.5 \pm 53.2$ & $75.6 \pm 3.2$ & $27.8 \pm 2.8^{*}$ & $0.4 \pm 0.06^{*}$ \\
Diabetic + $60 \mathrm{mg} / \mathrm{kg}$ extract & $249 \pm 64.8^{*}$ & $72 \pm 5.3^{*}$ & $25.7 \pm 4.5^{*}$ & $0.4 \pm 0.03^{*}$ \\
Diabetic + $120 \mathrm{mg} / \mathrm{kg}$ extract & $177.3 \pm 34^{*}$ & $71 \pm 11.2^{*}$ & $26.6 \pm 3.4^{*}$ & $0.41 \pm 0.03^{*}$ \\
\hline
\end{tabular}

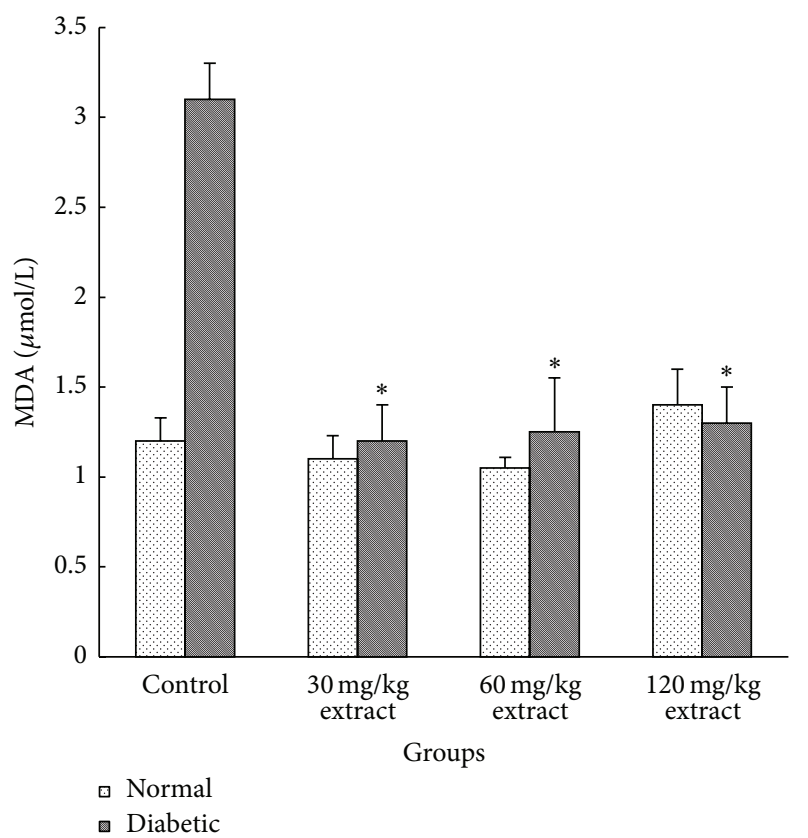

Figure 2: Mean values of malondialdehyde (MDA) in different groups (data shown as mean $\pm \mathrm{SEM}, n=8$ ). Extract consumption decreased the levels of MDA in comparison with control diabetic group. ${ }^{*} P<0.01$ in comparison with control diabetic group.

range of biological activity such as antidiabetic, anticancer, antioxidant, and antimicrobial [26-32].

In human, dietary consumption of high anthocyanins and anthocyanin-rich fruit, particularly blueberries, decreased the risk of T2DM [29]. Animal studies have shown that anthocyanin improves glucose metabolism, insulin resistance, and $\beta$-cell dysfunction via GLUT4 regulation $[26,27$, $33,34]$.

Antidiabetic effects of Peganum harmala extract may be due to antioxidant, enzyme inhibition, and receptor agonist or antagonist activity or through novel mechanisms yet to be clarified. One of the possible explanation mechanisms for hypoglycemic action of hydroalcoholic extract of Peganum harmala seed may be due to enhanced insulin secretion from residual pancreatic $\beta$-cells from diabetic rats. Our data showed that Peganum harmala can decrease $\mathrm{HbA}_{1 \mathrm{C}}$ in diabetic rats, which emphasizes the hypoglycemic effect of

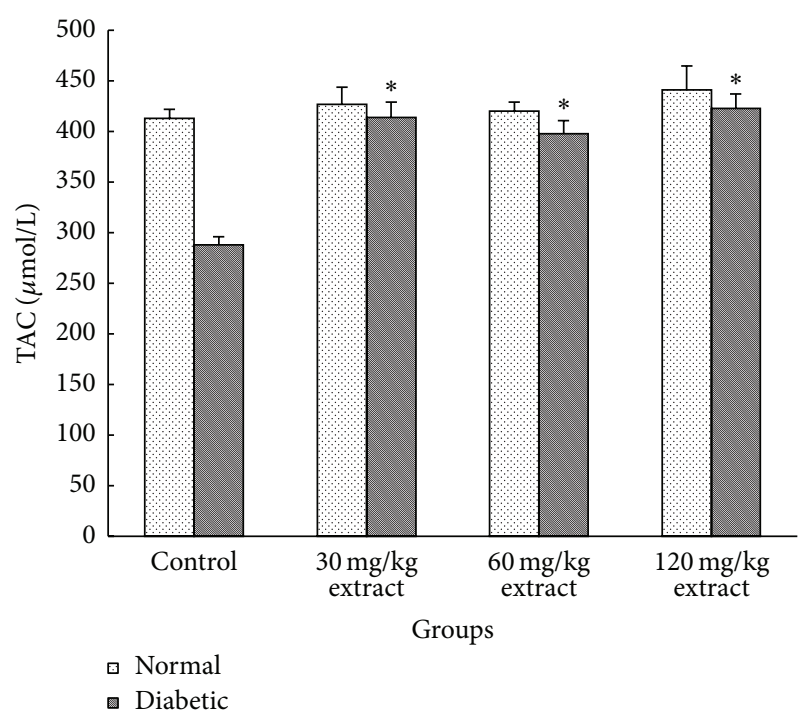

FIGURE 3: Mean values of total antioxidant capacity (TAC) in different groups. Extract consumption increased TAC in all doses (data shown as mean $\pm \mathrm{SEM}, n=8$ ). ${ }^{*} P<0.05$ in comparison with control diabetic group.

extract. Treatment of nondiabetic rats with Peganum harmala did not have any effect on glucose and $\mathrm{HbA}_{1 \mathrm{C}}$ level.

Hyperlipidemia is one of well-known complications of diabetes. Helpful effects of Peganum harmala on lipid profile also may relate to effect on carbohydrate metabolism or modification of hepatic enzymes or decrease in lipid peroxidation and oxidative stress. Antioxidants can reduce the oxidative stress and consequently ameliorate the progress of stress related diseases. This study showed that MDA level decreased and TAC increased after treatment with Peganum harmala in diabetic rats. The antioxidant activity of the extract could decrease the rate of LDL oxidation. Berrougui et al. [35] found that Peganum harmala extract contained harmaline and harmine alkaloids. They showed that these compounds had significant free radical scavenging capacity and inhibited lipid peroxidation of LDLs.

Some of the harmful effects of diabetes may relate to hepatic dysfunction and may be corrected after use of Peganum harmala extract in diabetic rats. Our data revealed that liver function tests such as ALT, AST, GGT, and bilirubin change 
after diabetes induction and are modified after treatment which indicate that Peganum harmala extract possesses liver damage recovering effects.

It has been shown that aqueous extracts of Peganum harmala at dose of $300 \mathrm{mg} / \mathrm{kg}$ of body weight for 60 days might have adverse effects on the processes of spermatogenesis via direct or indirect effects on somniferous tubules and/or the pituitary testicular axis [36]. Oral administration of aqueous extract of Peganum harmala for six times a week at doses of $1,1.35$, and $2 \mathrm{~g} / \mathrm{kg}$ during 3 -month period increased transaminases in rats [37]. Histological findings revealed liver degeneration and spongiform changes in the central nervous system in rats treated with $2 \mathrm{~g} / \mathrm{kg}$ dose but not at the therapeutic dose of $1 \mathrm{~g} / \mathrm{kg}$.

One limitation of the current study is that we did not perform histological evaluation of organs and tissues of Peganum harmala treated rats. The other limitation is that we did not determine the insulin level and pancreatic islet $\beta$-cell recovering effect of Peganum harmala extract.

\section{Conclusion}

Taken together, our findings indicate that hydroalcoholic extract of Peganum harmala exhibits antidiabetic and hypolipidemic activities in streptozotocin-induced diabetic male rats. Further studies are needed to establish the components of the extract and the mechanism(s) by which the extract utilizes its effects.

\section{Competing Interests}

The authors declare that they have no competing interests.

\section{Acknowledgments}

The authors are grateful to the Vice Chancellor for Research of Zahedan University of Medical Science for their financial support of the M.S. thesis of Mohsen Bameri-Niafar. The authors acknowledge the Departments of Physiology and Biochemistry at Zahedan University of Medical Sciences for the support provided for this work.

\section{References}

[1] IDF, IDF Diabetes Atlas, International Diabetes Federation, 6th edition, 2013.

[2] WHO, "World Health Organization: diabetes," Fact Sheet 312, 2015, http://www.who.int/mediacentre/factsheets/fs312/en/.

[3] Y. S. Choi, S. K. Lee, W. J. Bae et al., "Bariatric surgery improves the cavernosal neuronal, vasorelaxation, and contraction mechanisms for erectile dysfunction as result of amelioration of glucose homeostasis in a diabetic rat model," PLOS ONE, vol. 9, no. 8, Article ID e104042, 2014.

[4] K. Carolo Dos Santos, C. Pereira Braga, P. Octavio Barbanera, F. Rodrigues Ferreira Seiva, A. Fernandes Jr., and A. A. Henrique Fernandes, "Cardiac energy metabolism and oxidative stress biomarkers in diabetic rat treated with resveratrol," PLoS ONE, vol. 9, no. 7, Article ID e102775, 2014.
[5] P. Koroglu, G. E. Senturk, D. Yucel, O. B. Ozakpinar, F. Uras, and S. Arbak, "The effect of exogenous oxytocin on streptozotocin (STZ)-induced diabetic adult rat testes," Peptides, vol. 63, pp. 4754, 2014.

[6] J. Bolsinger, A. Pronczuk, R. Sambanthamurthi, and K. C. Hayes, "Anti-diabetic effects of palm fruit juice in the Nile rat (Arvicanthis niloticus)," Journal of Nutritional Science, vol. 3, article e5, 2014.

[7] A. B. Singh, J. P. Chaturvedi, T. Narender, and A. K. Srivastava, "Preliminary studies on the hypoglycemic effect of Peganum harmala L. seeds ethanol extract on normal and streptozotocin induced diabetic rats," Indian Journal of Clinical Biochemistry, vol. 23, no. 4, pp. 391-393, 2008.

[8] T. Herraiz, D. González, C. Ancín-Azpilicueta, V. J. Arán, and H. Guillén, " $\beta$-Carboline alkaloids in Peganum harmala and inhibition of human monoamine oxidase (MAO)," Food and Chemical Toxicology, vol. 48, no. 3, pp. 839-845, 2010.

[9] M. A. Berdai, S. Labib, and M. Harandou, "Peganum harmala L. Intoxication in a pregnant woman," Case Reports in Emergency Medicine, vol. 2014, Article ID 783236, 3 pages, 2014.

[10] H. Shao, X. Huang, Y. Zhang, and C. Zhang, "Main alkaloids of Peganum harmala L. and their different effects on dicot and monocot crops," Molecules, vol. 18, no. 3, pp. 2623-2634, 2013.

[11] S. Bensalem, J. Soubhye, I. Aldib et al., "Inhibition of myeloperoxidase activity by the alkaloids of Peganum harmala L. (Zygophyllaceae)," Journal of Ethnopharmacology, vol. 154, no. 2, pp. 361-369, 2014.

[12] F. Lamchouri, A. Settaf, Y. Cherrah et al., "In vitro celltoxicity of Peganum harmala alkaloids on cancerous cell-lines," Fitoterapia, vol. 71, no. 1, pp. 50-54, 2000.

[13] A. M. Sobhani, S.-A. Ebrahimi, and M. Mahmoudian, "An in vitro evaluation of human DNA topoisomerase I inhibition by Peganum harmala L. seeds extract and its $\beta$-carboline alkaloids," Journal of Pharmacy and Pharmaceutical Sciences, vol. 5, no. 1, pp. 19-23, 2002.

[14] H. R. Monsef, A. Ghobadi, M. Iranshahi, and M. Abdollahi, "Antinociceptive effects of Peganum harmala L. alkaloid extract on mouse formalin test," Journal of Pharmacy \& Pharmaceutical Sciences, vol. 7, no. 1, pp. 65-69, 2004.

[15] V. K. Singh, V. Mishra, S. Tiwari et al., "Anti-secretory and cytoprotective effects of peganine hydrochloride isolated from the seeds of Peganum harmala on gastric ulcers," Phytomedicine, vol. 20, no. 13, pp. 1180-1185, 2013.

[16] L. Zuo, Y. Du, M. Lu et al., "Atorvastatin inhibits hyperglycemiainduced expression of osteopontin in the diabetic rat kidney via the p38 MAPK pathway," Molecular Biology Reports, vol. 41, no. 4, pp. 2551-2558, 2014.

[17] J. R. MacDonald, M. Oellermann, S. Rynbeck et al., “Transmural differences in respiratory capacity across the rat left ventricle in health, aging, and streptozotocin-induced diabetes mellitus: evidence that mitochondrial dysfunction begins in the subepicardium," American Journal of Physiology-Cell Physiology, vol. 300, no. 2, pp. C246-C255, 2011.

[18] A. J. S. Fox, A. Bedi, X.-H. Deng et al., "Diabetes mellitus alters the mechanical properties of the native tendon in an experimental rat model," Journal of Orthopaedic Research, vol. 29, no. 6, pp. 880-885, 2011.

[19] M. Karajibani, M. Hashemi, F. Montazerifar, A. Bolouri, and M. Dikshit, "The status of glutathione peroxidase, superoxide dismutase, vitamins A, C, E and malondialdehyde in patients with cardiovascular disease in Zahedan, Southeast Iran," Journal of 
Nutritional Science and Vitaminology, vol. 55, no. 4, pp. 309-316, 2009.

[20] M. Hashemi, H. Mehrabifar, M. Daliri, and S. Ghavami, "Adenosine deaminase activity, trypsin inhibitory capacity and total antioxidant capacity in psoriasis," Journal of the European Academy of Dermatology and Venereology, vol. 24, no. 3, pp. 329-334, 2010.

[21] I. F. F. Benzie and J. J. Strain, "The ferric reducing ability of plasma (FRAP) as a measure of "antioxidant power": the FRAP assay," Analytical Biochemistry, vol. 239, no. 1, pp. 70-76, 1996.

[22] M. Moloudizargari, P. Mikaili, S. Aghajanshakeri, M. H. Asghari, and J. Shayegh, "Pharmacological and therapeutic effects of Peganum harmala and its main alkaloids," Pharmacognosy Reviews, vol. 7, no. 14, pp. 199-212, 2013.

[23] A. J. Tanweer, N. Chand, U. Saddique, C. A. Bailey, and R. U. Khan, "Antiparasitic effect of wild rue (Peganum harmala L.) against experimentally induced coccidiosis in broiler chicks," Parasitology Research, vol. 113, no. 8, pp. 2951-2960, 2014.

[24] F. Khoshzaban, F. Ghaffarifar, and H. R. J. Koohsari, "Peganum harmala aqueous and ethanol extracts effects on lesions caused by Leishmania major (MRHO/IR/75/ER) in BALB/c mice," Jundishapur Journal of Microbiology, vol. 7, no. 7, Article ID e10992, 2014.

[25] R. Zamora-Ros, C. Sacerdote, F. Ricceri et al., "Flavonoid and lignan intake in relation to bladder cancer risk in the European prospective investigation into cancer and nutrition (EPIC) study," British Journal of Cancer, vol. 111, no. 9, pp. 1870-1880, 2014.

[26] A. Crozier, I. B. Jaganath, and M. N. Clifford, "Dietary phenolics: chemistry, bioavailability and effects on health," Natural Product Reports, vol. 26, no. 8, pp. 1001-1043, 2009.

[27] D. Del Rio, G. Borges, and A. Crozier, "Berry flavonoids and phenolics: bioavailability and evidence of protective effects," British Journal of Nutrition, vol. 104, supplement 3, pp. S67-S90, 2010.

[28] H. de Groot and U. Rauen, "Tissue injury by reactive oxygen species and the protective effects of flavonoids," Fundamental and Clinical Pharmacology, vol. 12, no. 3, pp. 249-255, 1998.

[29] N. M. Wedick, A. Pan, A. Cassidy et al., "Dietary flavonoid intakes and risk of type 2 diabetes in US men and women," American Journal of Clinical Nutrition, vol. 95, no. 4, pp. 925933, 2012.

[30] C. J. Schorah, "Micronutrients, vitamins, and cancer risk," Vitamins \& Hormones, vol. 57, pp. 1-23, 1999.

[31] N. Tajuddeen, M. S. A. Sallau, A. M. U. Musa, D. J. A. Habila, and S. M. U. Yahaya, "Flavonoids with antimicrobial activity from the stem bark of Commiphora pedunculata (Kotschy \& Peyr.) Engl," Natural Product Research, vol. 28, no. 21, pp. 1915-1918, 2014.

[32] N. Chabir, H. Ibrahim, M. Romdhane et al., "Seeds of Peganum harmala L. chemical analysis, antimalarial and antioxidant activities, and cytotoxicity against human breast cancer cells," Medicinal Chemistry, vol. 11, no. 1, pp. 94-101, 2015.

[33] S. J. Zunino, "Type 2 diabetes and glycemic response to grapes or grape products," Journal of Nutrition, vol. 139, no. 9, pp. 1794S1800S, 2009.

[34] P. V. A. Babu, D. Liu, and E. R. Gilbert, "Recent advances in understanding the anti-diabetic actions of dietary flavonoids," Journal of Nutritional Biochemistry, vol. 24, no. 11, pp. 1777-1789, 2013.
[35] H. Berrougui, M. Isabelle, M. Cloutier, M. Hmamouchi, and A. Khalil, "Protective effects of Peganum harmala L. extract, harmine and harmaline against human low-density lipoprotein oxidation," The Journal of Pharmacy and Pharmacology, vol. 58, no. 7, pp. 967-974, 2006.

[36] Q. A. El-Dwairi and S. M. Banihani, "Histo-functional effects of Peganum harmala on male rat's spermatogenesis and fertility," Neuroendocrinology Letters, vol. 28, no. 3, pp. 305-310, 2007.

[37] F. Lamchouri, A. Settaf, Y. Cherrah et al., "Experimental toxicity of Peganum harmala seeds," Annales Pharmaceutiques Francaises, vol. 60, no. 2, pp. 123-129, 2002. 


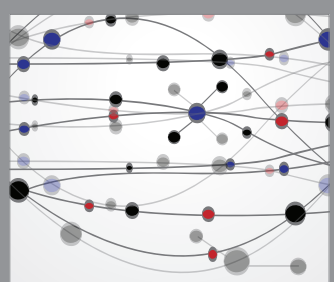

The Scientific World Journal
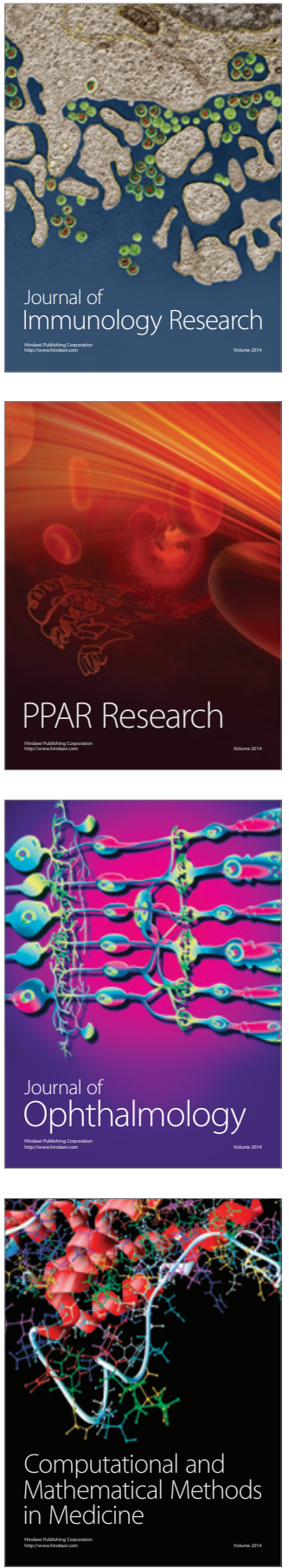

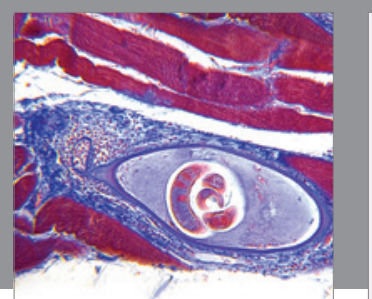

Gastroenterology Research and Practice

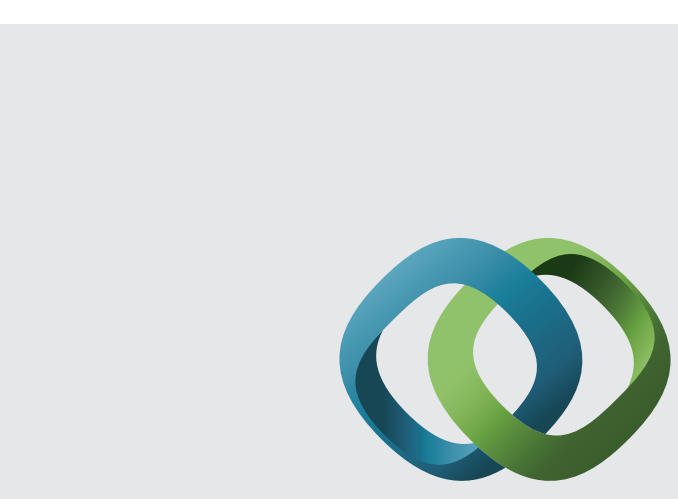

\section{Hindawi}

Submit your manuscripts at

http://www.hindawi.com
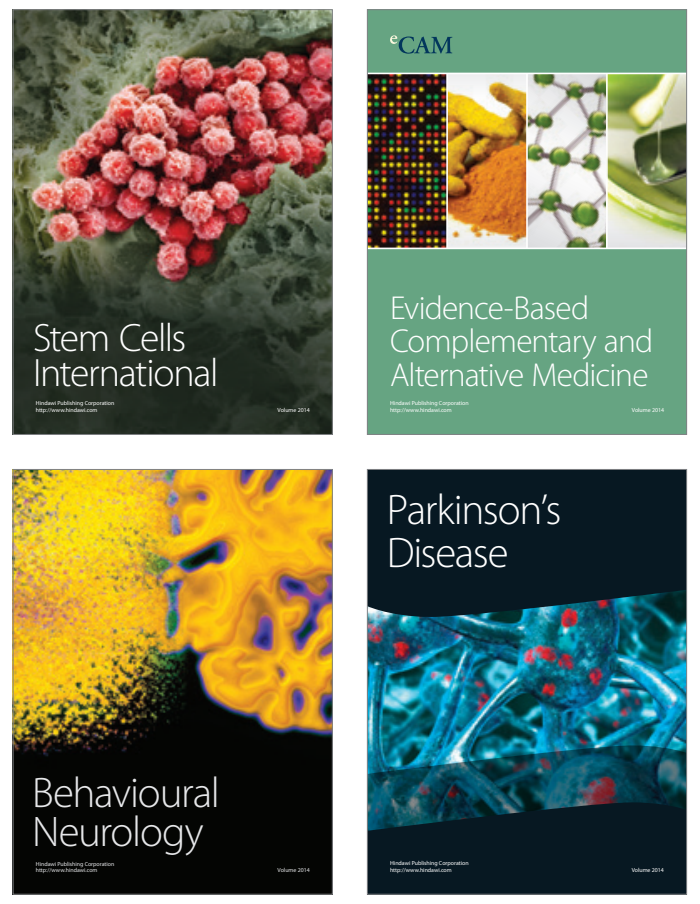
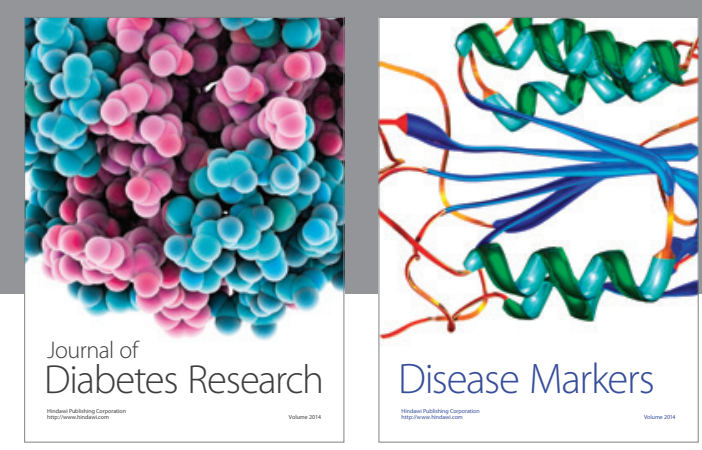

Disease Markers
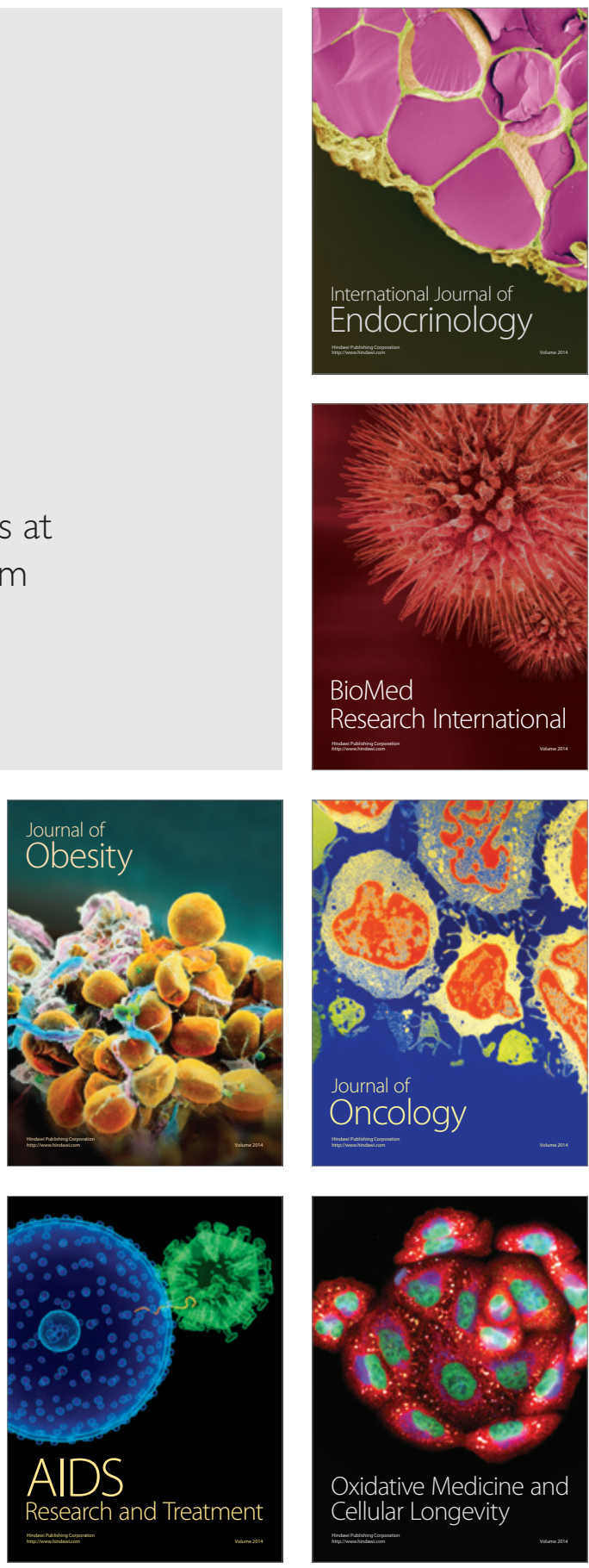